\title{
Interrelationship between Colicin Sensitivity and Phage Resistance
}

\author{
By F. H. MUKAI* \\ Department of Zoology, Columbia University, Nerw York, New York, U.S.A.
}

(Received 30 May 1960)

\begin{abstract}
SUMMARY
When cultures of Escherichia coli strain 15 were irradiated with ultraviolet radiation, the bacteria were induced to form a bactericidal material, colicin-15. Colicin-15 was released by the lysis of bacteria which underwent a residual growth without division. The only strains of bacteria sensitive to the action of colicin-15 were derivatives of strain 15. Three colicin-resistant strains were obtained, all of which became simultaneously sensitive to every $\mathbf{T}$-phage, while the colicin-sensitive parental strains were lysed only by T2. By stepwise reversal of the phage sensitivity pattern, it was possible to revert colicin-resistant mutants to colicin sensitivity again. Only certain mutations conferring resistance in concert to phages $\mathbf{T} \mathbf{1}$, T3, T4, T5 and T7 seemed to result in colicin sensitivity. A model which will account for these phenomena is presented.
\end{abstract}

\section{INTRODUCTION}

Certain strains of bacteria possess the inherent capacity to produce specific substances which have lethal effects on other related bacterial strains. The antagonism between two strains of Escherichia coli was first described by Gratia (1925), who found that the filtrate from a culture of $E$. coli $\mathrm{V}$ greatly inhibited the growth of $E$. $\operatorname{coli} \phi$. It was later shown that strain $\mathrm{V}$ produced an antibiotic substance active against strain $\phi$ (Gratia, 1932). The frequent occurrence of such reciprocal antibiotic action among many strains of $E$. coli was demonstrated by Fredericq (1946a), and the substances responsible for the lethal effects were named 'colicins'. Further investigations of numerous enteric bacteria revealed that similar substances were also formed by some strains of $E$. freundii (Fredericq, 1947), a few Salmonella strains (Fredericq, 1952; Hamon, 1955), and many Shigella strains (Fredericq, 1948 $a$; Fastier, 1949). Moreover, analogous substances were found in three other families of bacteria: pyocin, produced by Pseudomonas pyocyanea (aeruginosa) (Jacob, 1954); megacin, produced by Bacillus megaterium (Ivanovics \& Alföldi, 1954); and pesticin, produced by Pasteurella pestis (Ben-Gurion \& Hertman, 1958). A more general term 'bacteriocin' was proposed (Jacob, Lwoff, Siminovitch \& Wollman, 1953) for these substances, since the name colicin was originally intended to characterize the antibiotic principle from $E$. coli.

* Present address : Department of Genetics, Carnegie Institution of Washington, Cold Spring Harbor, New York. 
Colicins differ in the extent and specificity of their activity, and in their physical and chemical properties (Fredericq, 1948b; Goebel, Barry \& Shedlovsky, 1956; Hamon, 1956; Ludford \& Lederer, 1953). Usually, a colicinogenic strain of bacteria spontaneously produces a specific colicin which is effective against another strain. Under conditions similar to those which cause induction of temperate phage in lysogenic bacteria, Jacob, Siminowitch \& Wollman (1952) showed that it was possible to induce the formation of colicin by ultraviolet (u.v.) irradiation. The genetic capacity to form colicins resides in transmissible units, procolicins, which behave much as do prophage in lysogenic bacteria. Ryan, Fried \& Mukai (1955) reported the existence of a u.v.-inducible colicinogenic strain which was susceptible to the colicin it produced. The present paper describes the induction of colicin synthesis in this strain, and the specificity of action of the colicin produced.

\section{METHODS}

Bacteria. The thymine- and histidine-requiring strains of Escherichia coli used in these experiments were originally secured after X-ray treatment of the wild type strain 15, American Type Culture Collection No. 9723 (Roepke, Libby \& Small, 1944). The author is grateful to Dr S. B. Greer for the thymineless strain, hereafter designated t-CS, and to Dr F. J. Ryan for the histidineless strain, h-CS. The notation ' $\mathrm{CS}$ ' is used to signify colicin sensitivity. All stock cultures were maintained at $5^{\circ}$ on nutrient agar slopes.

Phages. The seven phages of the T-series were used (Delbrück, 1946). High titre phage stocks $\left(10^{9}-10^{11}\right.$ particles $/ \mathrm{ml}$.) were prepared by infecting growing cultures of Escherichia coli B with each of the seven phages. Following mass lysis, the cultures were centrifuged at low speed to remove bacterial debris, and the supernatant fluids shaken with chloroform to kill remaining viable bacteria. The stock suspensions thus obtained were stored at $5^{\circ}$ in screw-cap test tubes.

Media. For all colicin experiments a modified Gray \& Tatum's defined medium (Ryan \& Schneider, 1949), supplemented with $0.06 \%(\mathrm{w} / \mathrm{v})$ glucose, and either $2 \mu \mathrm{g}$. thymine $/ \mathrm{ml}$. or $25 \mu \mathrm{g}$. histidine $/ \mathrm{ml}$. was used. Agar medium was prepared by adding $20 \mathrm{~g}$ agar/l. liquid medium and increasing the concentration of glucose to $0.5 \%(w / v)$.

For phage experiments, nutrient medium consisting of $8 \mathrm{~g} . / 1$. desiccated Difco nutrient broth $+0.5 \%(\mathrm{w} / \mathrm{v}) \mathrm{NaCl}$ was used (Adams, 1950). For plating, this nutrient medium was solidified with $1 \cdot 5 \%$ (w/v) agar.

U.v.-irradiation. U.v.-irradiations were performed with a $3.5 \mathrm{~W}$. Westinghouse Sterilamp WL 793, emitting predominantly at 2537 A. For the irradiation, one $\mathrm{ml}$. of a stationary phase culture of Escherichia coli strain t-CS or h-CS was inoculated into $100 \mathrm{ml}$. defined medium, giving a suspension containing $c .5 \times 10^{6} \mathrm{bacteria} / \mathrm{ml}$. After 4 to $5 \mathrm{hr}$. of aerated growth at $37^{\circ}$, when the bacteria were in the logarithmic phase of growth and at a concentration of $4-8 \times 10^{7}$ organisms $/ \mathrm{ml}, 15 \mathrm{ml}$. samples were distributed into Petri dishes and exposed to various doses of u.v. radiation. After irradiation, duplicate $6 \mathrm{ml}$. samples were pipetted into $16 \times 150 \mathrm{~mm}$. test tubes and incubated at $37^{\circ}$ until maximal clearing. The growth of the cultures was measured turbidometrically in a Klett-Summerson colorimeter fitted with a no. 59 filter. For unirradiated cultures there was a linear relationship between total number 
of bacteria $/ \mathrm{ml}$. and the colorimeter reading as found for this strain by Ryan \& Schneider (1948). After maximal clearing, 0.2 ml. chloroform was added to one of each pair of tubes which were then shaken vigorously for 15 sec. and centrifuged; the supernatant fluids were saved for subsequent testing of bactericidal activity. The growth in the second group of tubes was followed until the cultures reached a stationary phase due to the exhaustion of glucose. The supernatant fluids of these tubes were kept as before. All operations during and after irradiation were conducted under yellow light to prevent photoreversal of the u.v. effects (Jacob et al. 1952).

Demonstration of bactericidal activity. Approximately $5 \times 10^{7}$ organisms (unirradiated strain t-CS or h-CS) were spread on the surface of defined medium agar plates which had been previously dried at $37^{\circ}$ for 2 days. Measured samples, usually $0.05 \mathrm{ml}$. of the supernatant fluids obtained following u.v. induction, were placed on the seeded plates. The plates were kept at room temperature until the drops had dried, and were then incubated at $37^{\circ}$ for $16 \mathrm{hr}$. Antibacterial activity was manifested by the fact that, except for a few isolated colonies, no growth occurred in the area covered by the drops. Cell-free supernatant fluids from unirradiated cultures were used as controls. The small colonies within the clear areas consisted of bacteria which did not grow when transferred to nutrient agar slopes. When a twofold dilution was made of active lysates, the clarity of the spots faded markedly, and no unequivocal estimate of colicin titre could be made. Therefore, only undiluted supernatant fluids were used to test for antibacterial activity.

Isolation of phage-resistant mutants. Approximately $10^{9}$ organisms from a brothgrown culture of the phage-sensitive strains were spread on the surface of nutrient agar plates. Duplicate plates were spotted with $0.1 \mathrm{ml}$. of high titre stock suspension or the different phages, with no more than three spots to a plate. The drops were allowed to spread by tilting the plates, care being taken to prevent merging and mixing of the phages. After the drops had dried, the plates were incubated at $37^{\circ}$ for 16-24 $\mathrm{hr}$. before observation and isolation of colonies of presumably resistant bacteria. These colonies were stabbed with a sterile needle, inoculated into $2 \mathrm{ml}$. of nutrient medium, and incubated for 6-8 hr. until a majority of the tubes became turbid. Whenever possible, at least five isolates were made for each viral strain. A preliminary test of resistance was made at this time by the cross-streaking method of Demerec \& Fano (1945). Suspensions of phage and bacteria were streaked at right angles on a nutrient agar plate. An isolate was classified as resistant to a phage when it showed no lysis at the intersection of the streaks. Such mutants were then purified by streaking on nutrient agar plates and making three successive isolations of single colonies. To make certain that mutants to be kept for further study had stemmed from independent mutations, only one isolate from a group was maintained unless some members of the group showed either a different crossresistance pattern, or a recognizable difference in colony morphology.

The notation of bacterial strains derived from phage-resistant colonies follows the system of Demerec \& Fano (1945). Thus, t-CR/5,1 indicates that the resistant strain was derived from t-CR after selecting with $\mathbf{T} 5$, and found to be cross-resistant to $\mathbf{T} 1$. 


\section{RESULTS}

\section{Induction of colicin synthesis}

An example of the behaviour of Escherichia coli strain t-CS cultures following exposure to various doses of u.v. radiation is shown in Fig. 1. After an initial increase in optical density lasting about $90 \mathrm{~min}$., a decrease in turbidity occurred. The extent of the initial increase diminished as the dose increased. Subsequently, a second increase in optical density at similar rates occurred and eventually reached a stable value. Bactericidal activity was present in the supernatant fluids of all of the irradiated cultures, taken either at the time of maximal clearing or after the stationary phase of growth was reached. Qualitatively, the activity was highest in the supernatant fluids of the cultures which showed maximal growth before lysis. No activity was found in the unirradiated controls.

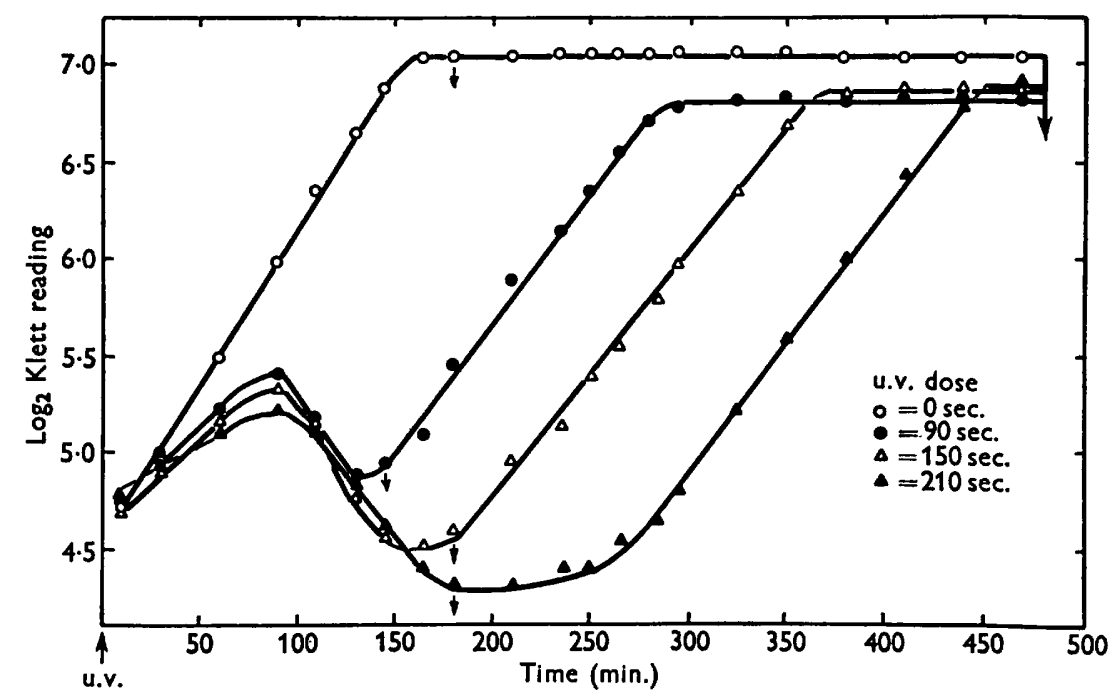

Fig. 1. Growth after u.v.-irradiation of cultures of Escherichia coli, t-CS, in defined medium. Arrows indicate times at which cultures were centrifuged to obtain supernatant fluids.

The initial increase in optical density was not the result of the division of those bacteria which survived the irradiation. This was determined by plating for surviving bacteria at intervals following induction (Table 1). Since coli strain t-CS is sensitive to the colicin it produces, a colicin-resistant mutant derived from coli strain t-CS was used as a control. An inducing dose of u.v. radiation which gave a maximal post-irradiation rise in turbidity was used. Rather than an increase in colony formers associated with the increase in optical density, a gradual decrease was observed with both strains. Bactericidal activity was found in the supernatant fluids only after the cultures showed a decrease in turbidity.

Microscopic observation of the induced cultures revealed the following changes in morphology of the bacteria: during the initial period after irradiation, $c .90 \%$ of the organisms gradually elongated and became less motile. The elongation proceeded uniformly, and after $c .100 \mathrm{~min}$. the bacteria were two to three times their original 
length. There was no apparent increase in the total number of bacteria. While actual lysis was not observed, there was a sudden decrease in the number of elongated bacteria concomitant with the decrease in optical density. The second rise in Klett readings was correlated with the increase of regular-sized rod-shaped bacteria which increased in number with time.

On the basis of these experiments, it is concluded that the residual growth without division of induced cultures represented a latent period during which colicin was being synthesized in those bacteria which elongated, and that the lysis of these bacteria released the colicin into the culture medium.

Table 1. Comparison between optical density and the number of viable bacteria after u.v. induction (90 sec. dose) of Escherichia coli strain t-CS and t-CR. The number of viable bacteria was determined by plating on defined medium agar supplemented with $2 \mu$ g. thymine/ml.

$\begin{array}{ccccc}\begin{array}{c}\text { Time after } \\ \text { u.v. irradiation } \\ \text { (min.) }\end{array} & \overbrace{\begin{array}{c}\text { Optical density } \\ \text { (Klett units) }\end{array}}^{\text {Strain t-CS }} & \begin{array}{c}\text { No. of viable } \\ \text { bacteria/ml. }\end{array} & \begin{array}{c}\text { Optical density } \\ \text { (Klett units) }\end{array} & \begin{array}{c}\text { No. of viable } \\ \text { bacteria/ml. }\end{array} \\ 0 & 54 & 9 \cdot 7 \times 10^{6} & 58 & 9 \cdot 6 \times 10^{6} \\ 20 & 58 & 1 \cdot 6 \times 10^{6} & 66 & 1 \cdot 9 \times 10^{6} \\ 40 & 65 & 1 \cdot 2 \times 10^{6} & 73 & 1 \cdot 7 \times 10^{6} \\ 60 & 72 & 6 \cdot 4 \times 10^{5} & 80 & 1 \cdot 1 \times 10^{5} \\ 80 & 74 & 7 \cdot 7 \times 10^{5} & 79 & 7 \cdot 0 \times 10^{5} \\ 100 & 67 & 1 \cdot 1 \times 10^{6} & 62 & 1 \cdot 0 \times 10^{6} \\ 120 & 53 & 1 \cdot 1 \times 10^{6} & 47 & 1 \cdot 1 \times 10^{6}\end{array}$

Post-irradiation death of the sort described above was reported by Lieb (1951). She suggested that two types of survivors of u.v. irradiation were present immediately after irradiation: (i) 'liquid resistants' which divided at normal rates in liquid medium; (ii) 'liquid sensitives' which died when placed in liquid medium, but which survived when plated immediately. In the present experiments, it is not known whether or not the bacteria which died when left in liquid medium were included among the bacteria which elongated and produced colicin.

\section{Transitory and heritable resistance to colicin-15}

Since bactericidal activity was found in the supernatant fluids of induced cultures which had reached a stationary value of optical density, it was presumed that the bacteria present were colicin-resistant. One possibility for the presence of such resistant organisms would be that the stock culture of coli strain t-CS was heterogeneous, containing some resistant and some sensitive bacteria. However, when 15 single-colony isolates were made from coli strain t-CS, each isolate showed the same behaviour as the parental culture, producing the same colicin in response to induction which was active against itself and the parent. Moreover, when induced cultures which had reached a stationary value were centrifuged and the organisms used as indicator bacteria, they proved to be equally sensitive to colicin-15 as were organisms of unirradiated cultures. The isolation and test of clones from $20 \mathrm{such}$ organisms confirmed this result.

Further evidence for the transitory resistance indicated above was shown by another method of testing for colicin activity; this consisted of plating for viable 
bacteria following exposure to colicin (Jacob et al. 1952). Tenfold dilutions were made of a stationary phase culture of coli strain t-CS and $0.1 \mathrm{ml}$. samples of these dilutions were suspended in $\mathbf{0 . 9} \mathrm{ml}$. of an active sample of colicin-15. After standing at room temperature for $30 \mathrm{~min}$., appropriate dilutions were plated for viable bacteria. Colonies were counted after incubation for 2 days at $37^{\circ}$. The results of such platings are shown in Table 2. Regardless of the initial number of bacteria, from 22 to $39 \%$ survived. When ten survivors from each dilution were isolated and tested for sensitivity, all forty isolates proved to be sensitive. The survival of organisms which grow after exposure to active lysates must be explained as a result of some sort of transitory resistance, the nature of which is unknown.

Nevertheless, two different mutants of coli strain 15 were secured which possessed a heritable resistance to colicin-15, one from coli strain t-CS and the other from coli strain $\mathrm{h}-\mathrm{CS}$, designated $\mathrm{t}-\mathrm{CR}$ and $\mathrm{h}-\mathrm{CR}$, respectively. These mutants were

Table 2. Survival of Escherichia coli, strain t-CS, exposed to colicin-15. The number of bacteria was determined by plating on defined medium agar supplemented with $2 \mu$ g. thymine/ml.

$\begin{array}{ccc}\begin{array}{c}\text { Initial no. } \\ \text { of bacteria }\end{array} & \begin{array}{c}\text { Final no. } \\ \text { of bacteria }\end{array} & \begin{array}{c}\text { Surviving } \\ \text { fraction }(\%)\end{array} \\ 4 \cdot 1 \times 10^{8} & 1 \cdot 1 \times 10^{6} & 27 \\ 4.0 \times 10^{5} & 1 \cdot 3 \times 10^{5} & 33 \\ 4 \cdot 0 \times 10^{4} & 8 \cdot 6 \times 10^{3} & 22 \\ 4.9 \times 10^{3} & 1 \cdot 8 \times 10^{3} & 39 \\ & & \text { Average } 30\end{array}$

found as viable colonies which grew within the clear areas during routine testing of colicin activity. Besides being heritably resistant to colicin-15, both mutants were sensitive to all seven T-phages. Both parental coli strains h-CS and t-CS, on the other hand, were sensitive only to phage $\mathrm{T} 2$; this sensitivity could be clearly shown by the cross-streak method only when tryptophan $(2 \mathrm{mg} . / \mathrm{ml}$.) was present. On the contrary, the CR coli strains sensitive to all seven phages showed a clear reaction to phage $\mathbf{T} \mathbf{2}$ in the absence of tryptophan. A change in sensitivity to T-phages was first reported by Ryan (1953) in his study of orthoselection in the coli strain h-CS. The fitter-type mutant obtained was also found to be sensitive to the seven T-phages, and resistant to the colicin it produced. This curious change to phage sensitivity in three independent colicin-resistant mutants suggested the existence of a correlation between colicin sensitivity and phage resistance. It was of interest to determine whether changes of the phage-sensitive phenotype in colicin-resistant mutants would restore colicin sensitivity.

\section{Relationship between colicin sensitivity and phage resistance}

When phage-resistant strains selected by each of the seven T-phages were checked for their cross-resistance pattern, a grouping similar to that obtained for Escherichia coli B (Demerec \& Fano, 1945) was found; this is shown in Table 3. None of these single-step mutants was sensitive to colicin-15. Thus, resistance to one or a few phages did not result in a loss of colicin resistance.

Since the colicin-sensitive parental coli strains were sensitive only to phage $\mathbf{T} 2$, it was felt that colicin sensitivity might be restored only in strain having the same 
phage-resistance pattern. Therefore new mutants were obtained by selecting for additional mutations in these one-step mutants. The pedigrees of multiply-resistant strains obtained are represented for coli strains t-CR and h-CR in Figs. 2 and 3, respectively. Strains which became sensitive to colicin-15 were found only among those mutants that were resistant to at least phages $\mathrm{T} 1, \mathrm{~T} 3, \mathrm{~T} 4, \mathrm{~T} 5$ and $\mathrm{T} 7$. For

Table 3. Types of phage-resistant strains derived from Escherichia coli, strains $t$-CR, and $h-C R$, after selection with the $T$ phages

\begin{tabular}{|c|c|c|}
\hline $\begin{array}{l}\text { Parent } \\
\text { strain }\end{array}$ & $\begin{array}{c}\text { Selecting } \\
\text { phage }\end{array}$ & Mutant strains \\
\hline t-CR & $\left\{\begin{array}{l}\text { T1 } \\
\text { T2 } \\
\text { T3 } \\
\text { T4 } \\
\text { T5 } \\
\text { T6 } \\
\text { T7 }\end{array}\right.$ & $\begin{array}{l}\mathrm{t}-\mathrm{CR} / 1,5 \\
\mathrm{t}-\mathrm{CR} / 2 \\
\mathrm{t}-\mathrm{CR} / 3,7 ; \mathrm{t}-\mathrm{CR} / 3,4,7 \\
\mathrm{t}-\mathrm{CR} / 4,3 ; \mathrm{t}-\mathrm{CR} / 4,3,7 \\
\mathrm{t}-\mathrm{CR} / 5,1 \\
\mathrm{t}-\mathrm{CR} / 6 \\
\mathrm{t}-\mathrm{CR} / 7,3 ; \mathrm{t}-\mathrm{CR} / 7,3,4\end{array}$ \\
\hline h-CR & $\left\{\begin{array}{l}\text { T1 } \\
\text { T2 } \\
\text { T3 } \\
\text { T4 } \\
\text { T5 } \\
\text { T6 } \\
\text { T7 }\end{array}\right.$ & $\begin{array}{l}\text { h-CR/1, } \\
\text { (none) } \\
\text { h-CR/3,4;h-CR/4, 3, } 7 \\
\text { h-CR/4; h-CR } / 4,3 ; \mathrm{h}-\mathrm{CR} / 4,3,7 \\
\mathrm{~h}-\mathrm{CR} / 5,1 \\
\mathrm{~h}-\mathrm{CR} / 6 \\
\mathrm{~h}-\mathrm{CR} / 7,3 ; \mathrm{h}-\mathrm{CR} / 7,3,4\end{array}$ \\
\hline
\end{tabular}

example, coli strain t-CR/5, 1/3, 7 became sensitive to colicin only after it became resistant to phage $\mathrm{T} 4$. The presence or absence of phage $\mathrm{T} 6$ resistance did not affect colicin sensitivity.

On the other hand, resistance to the five essential phages did not automatically confer sensitivity to colicin. Thus colicin-resistant mutants were found which, in their reaction to these phages, were phenotypically similar to colicin-sensitive mutants. Such strains must be assumed to be genotypically dissimilar. The fact

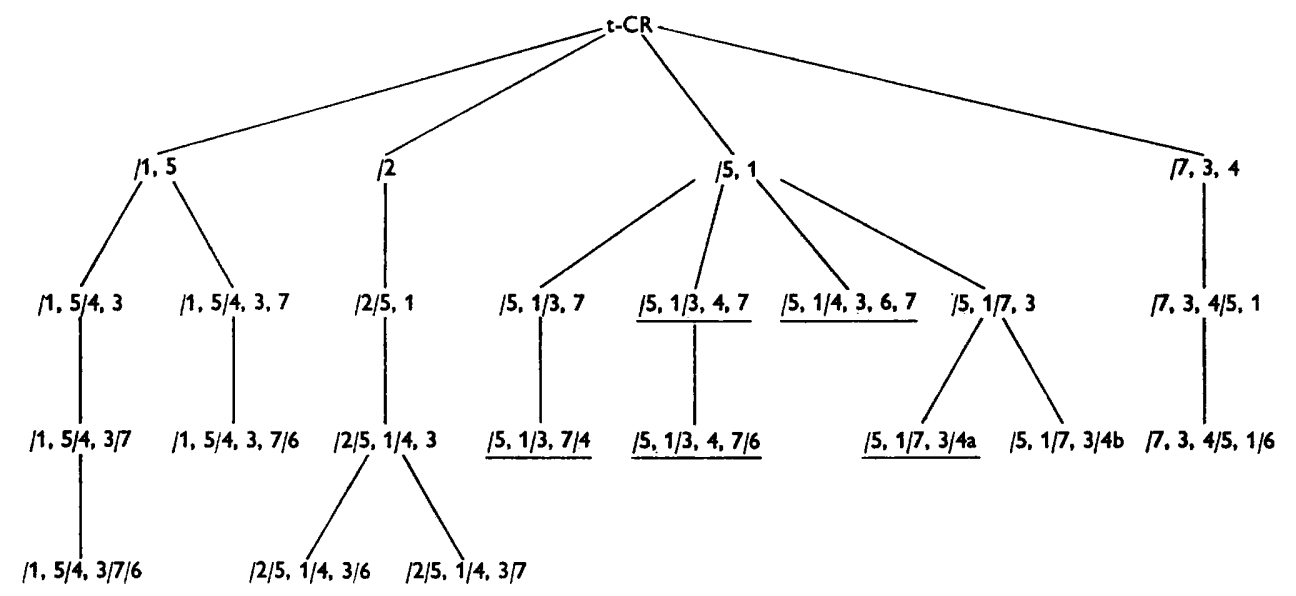

Fig. 2. The pedigree of phage-resistant strains derived from Escherichia coli, t-CR. For the sake of clarity, the notation for the parent strains has been omitted. Mutants sensitive to colicin-15 are underlined. 
that no colicin-sensitive mutants could be obtained from coli strain h-CR (Fig. 3) must similarly be attributed to genotypic differences, either between coli strains $\mathrm{h}-\mathrm{CR}$ and $\mathrm{t}-\mathrm{CR}$, or between the particular phage-resistant mutants derived therefrom. Indeed, it has been found that coli strain h-CR consistently showed a higher efficiency of plating with respect to phage T2 than did coli strain t-CR.

After transfer of the fertility agent, $\mathbf{F}^{+}$, to auxotrophic mutants of Escherichia coli B De Haan (1954) obtained genetic data for this previously infertile strain. Similar attempts to infect coli strain 15 with $\mathrm{F}^{+}$were unsuccessful. Since sexual recombination does not occur, the assumption of genotypic dissimilarity could not be experimentally ascertained. However, in bacterial strains where genetic analysis is possible, phenotypically similar phage-resistant mutants have been shown to be genotypically dissimilar (Lederberg, 1947; De Haan, 1954). Also, resistance to a given colicin has been shown to be determined by more than one locus (Fredericq, 1958).

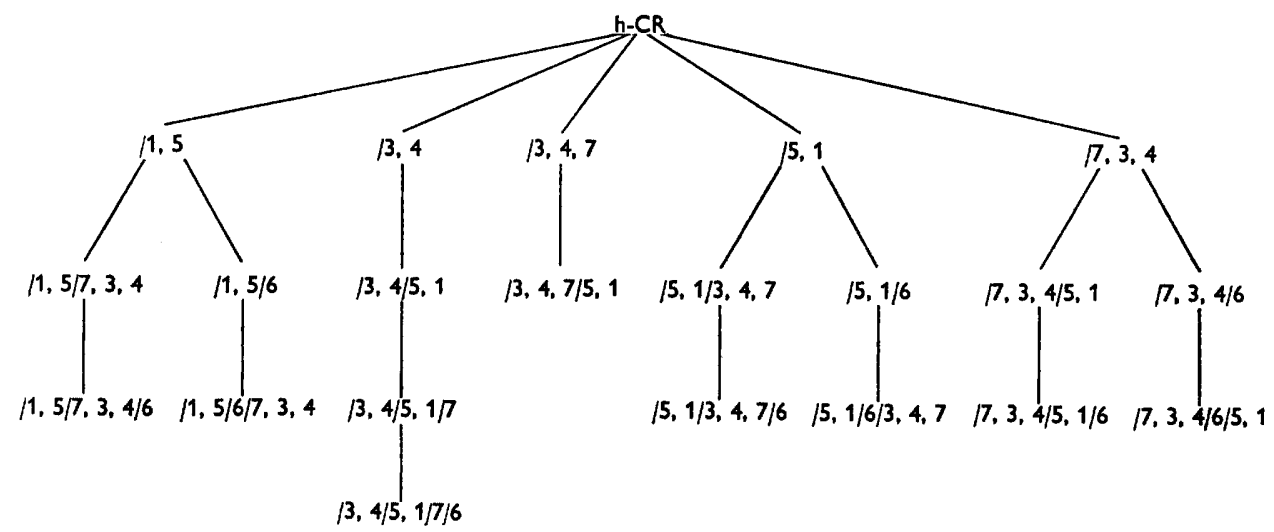

Fig. 3. The pedigree of phage-resistant strains derived from Escherichia coli, h-CR. For the sake of clarity, the notation for the parent strains has been omitted. No mutants were sensitive to colicin-15.

\section{The nature of colicin-15}

Before studies could be made on the properties of colicin-15, it was necessary to obtain a more sensitive indicator strain. Numerous strains of Escherichia coli other than strain 15, as well as Shigella sonnei, Bacillus megaterium, and Salmonella typhimurium were found to be resistant. The finding that colicin sensitivity in coli strain 15 was associated with resistance to phages $\mathbf{T} 1, \mathbf{T} 3, \mathbf{T} 4, \mathrm{~T} 5$, and $\mathrm{T} 7$ suggested the necessity of securing another strain of $\boldsymbol{E}$. coli with a similar phage-resistance phenotype. Strain B/1, 5/3, 4, 7 secured from $E$. coli B and strain $K 12 / 1,5 / 3,4,7$ secured from $E$. coli $\mathrm{K} 12$ were both resistant to colicin-15.

Fredericq (1957) demonstrated two different mechanisms of resistance to colicins : (i) resistance by loss of receptors; (ii) immunity by acquirement of ability to produce colicins. A strain possessing the receptor for colicin-E was made colicinogenic for colicin-E. The resulting strain became immune to this colicin while still keeping the corresponding receptor. Based on these findings, it was hoped that a non-colicinogenic mutant of coli strain 15 would retain its receptor for colicin-15. Attempts to secure such a mutant by u.v. irradiation (Ivanovics \& Nagy, 1958) or 
with cobalt chloride and acriflavine (Hirota, 1956, 1957; Furness \& Rowley, 1957) were unsuccessful. Also bacteria which survived heat treatment (Zamenhof \& Greer, 1958) or which had passed through the protoplast state did not lose the colicinogenic property.

The inability to find a good indicator strain precluded extensive investigations of the chemical, physical and biological properties of colicin-15. However, with coli strain 15, the following facts were observed. (1) Storage at $5^{\circ}$ for at least 1 year, or exposure to $8700 \mathrm{ergs}$ of $\mathrm{u} . \mathrm{v}$. radiation $/ \mathrm{mm} .^{2}$ did not result in a loss of bactericidal activity. (2) Heating at $70^{\circ}$ for $30 \mathrm{~min}$., or treatment with commercial trypsin for $10 \mathrm{hr}$. destroyed activity. (3) Filtration through a Millipore filter resulted in an appreciable loss of activity. (4) High speed centrifugation $(20,000 \mathrm{~g})$ for $30-60 \mathrm{~min}$. did not seem to result in loss of activity, but after $120 \mathrm{~min}$. there was no activity left in the supernatant fluid.

\section{DISCUSSION}

The induction of colicin-15 formation described here is analogous to the results of Jacob et al. (1952) for colicin ML and of Ivanovics \& Alfödi (1955, 1957) for megacin. In all these cases, a bacteriocin is released into the culture medium after a latent period followed by mass lysis of the induced bacteria. However, some authors (Fredericq, 1954, 1955; Hamon \& Lewe, 1955; Kellenberger \& Kellenberger, 1956) have concluded that induction of bacteriocin formation does not result in lysis unless the induced strains are also lysogenic. For example, Escherichia coli ML was found to be lysogenic, and lysis in this case was attributed to the development of temperate phages. The u.v. irradiation of a colicinogenic but non-lysogenic strain resulted in a residual growth of the bacteria, followed by a stationary phase without apparent lysis during which time the production of colicin occurred. On the other hand, megacin formation was shown to be invariably associated with the lysis of the induced bacteria. Fifty-two non-megacinogenic mutants derived from megacinogenic parents could not be made to lyse by exposure to u.v. irradiation (Ivanovics \& Nagy, 1958). Electron microscope studies of active lysates failed to demonstrate the presence of any phage particles, and it was concluded that the bacteriocinogenic character of Bacillus megaterium was not associated in the slightest degree with phage production (Ivanovics, Alfödi \& Lovas, 1957).

We have been unable to detect the presence of any virus in active lysates of colicin-15, although numerous phage-sensitive strains were used as indicators. However, such a finding still does not rule out the possibility that coli strain 15 is lysogenic. Arber \& Kellenberger (1958) made electron microscope examination of the lysates of seven defective-lysogenic strains derived from Escherichia coli $\mathrm{K} 12(\lambda)$. Although the lysates revealed no morphologically complete phages, each revealed the presence of phage-related structures: four of the strains produced empty heads and tails, while three produced heads only. All seven strains synthesized serum-blocking material (De Mars, 1955). Until similar studies are made, the possibility that our strains contain a defective prophage, the induction of which results in the synthesis of colicin-15, is not excluded.

Susceptibility to colicins has been shown to be controlled by a number of receptors, each specific for the colicin to which a strain is sensitive (Fredericq, 1946b). The existence of genetic factors controlling the presence or absence of the receptors was 
shown by recombination studies (Fredericq \& Betz-Bareau, 1952). Usually, a mutation affecting the receptor for one colicin does not affect the receptors for other colicins nor the receptors for bacteriophages. However, in the case of colicin- $K$ and phage T6, a specific cross-resistance was observed (Fredericq \& Gratia, 1950). Since all resistant mutants selected by either colicin-K or phage T6 were resistant to both agents simultaneously, it was concluded that a single receptor was shared by the two agents. A similar relationship was found for colicin-E and phage BF 23 (Fredericq, 1949).

The specificity of colicin-15 indicates that its activity also requires the presence of a specific receptor. In contrast to the reciprocal cross-resistance mentioned above, colicin-15 sensitivity shows an inverse relationship with phage-resistance. A formal scheme to explain this relationship is presented in Fig. 4. The diagram is

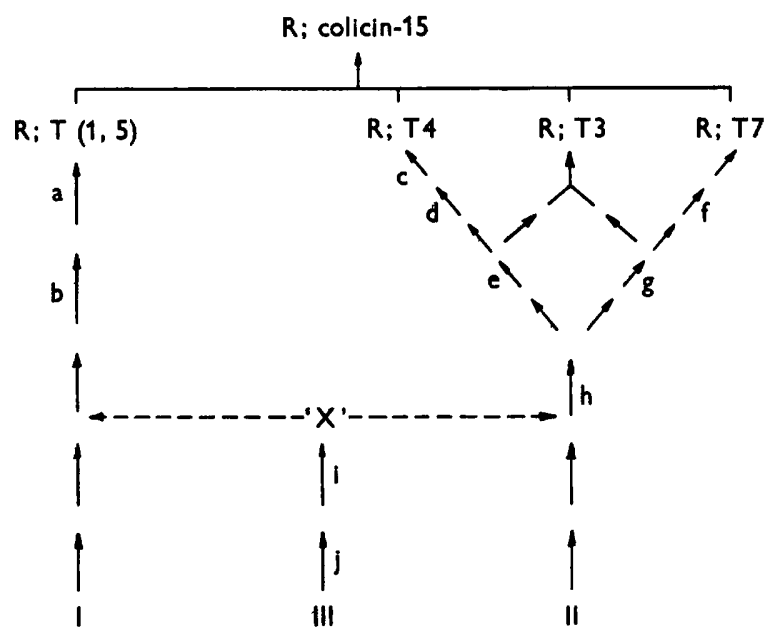

Fig. 4. Schematic representation of the relationship between colicin sensitivity and phage resistance. See text for explanation. $R=$ receptor site for the adsorption of phage (T) and colicin-15. a, b, c, d, e, f, g, h, i, j, = mutations resulting in alteration of receptor site.

a modification of the generalized scheme formulated by Anderson (1944), explaining interrelationships between phage-resistance and metabolic changes leading to increased growth requirements. The receptor site for colicin-15 is depicted as being composed of the receptor sites for phages $T(1,5), T 3, T 4$ and $T 7$. Since no mutants were found which were resistant to phage $\mathrm{T} 1$ or phage $\mathrm{T} 5$, alone, the receptor sites for these phages have been combined. Pathways I and II lead to the formation of elements which must be present to enable the bacteria to react with phages $T(1,5)$ and T3, T4 or T7, respectively. Mutational changes at a or $b$, would result in different alterations in $\mathbf{R}(1,5)$, while changes at $c, d, e, f, g$, or $h$ would result in different alterations in the respective receptor sites concerned. All of the phageresistant phenotypes observed (Figs. 3, 4) can be accounted for by this scheme. Since some mutants with the correct phage-resistant phenotype remained colicinresistant, it is necessary to require that a combination of precise mutant receptor sites is needed for colicin sensitivity. The possible role of the sequence in which the mutations occurred could not be elucidated. 
In order to explain the observation that a single change from colicin sensitivity to resistance (coli strain t-CS to strain t-CR and coli strain h-CS to strain h-CR) resulted in susceptibility to all phages, it is necessary to place pathways I and II under unit control. This can be done by a common factor ' $X$ ' formed by pathway III. The factor ' $\mathrm{X}$ ' might represent an element common to all phage receptor sites. If this were so, the parental CS coli strains would be geno-typically resistant to all T-phages except $\mathbf{T} 2$, and the mutation ( $\mathrm{i}$ or $\mathrm{j}$ ) to strain CR would result in the observed sensitivity to the phages. In this case, it should have been possible to obtain a one-step mutant which became simultaneously phage-resistant and colicinsensitive. Such a strain was not found. On the other hand, ' $X$ ' might be an element which exerted an epistatic effect on the phage receptor sites. In this event, the parental strains would be phenotypically phage-resistant but genotypically sensitive. The mutation to $\mathrm{CR}$ would result in the removal of ' $\mathrm{X}$ ', allowing the expression of the phage-sensitive phenotype. Since reversal to colicin sensitivity required stepwise mutations to multiple phage-resistance, evidence exists for the second role of factor ' $X$ '. However, in the absence of recombination data, we cannot conclusively distinguish between the two alternatives.

The author wishes to express his appreciation to Professor F. J. Ryan for his guidance, interest and encouragement throughout the course of this investigation. The work described in this paper was submitted in partial fulfilment of the requirements for the degree of Doctor of Philosophy, in the Faculty of Pure Science, Columbia University. The author is Public Health Service Research Fellow of the National Cancer Institute.

This work was supported in part by grants from the American Cancer Society, the U.S. Public Health Service and the National Science Foundation administered by Professor F. J. Ryan.

\section{REFERENCES}

Adams, M. H. (1950). Methods of study of bacterial viruses. Methods in Medical Research. Vol. 2. Yearbook Publishers, Inc., Chicago, U.S.A.

ANDErson, E. H. (1944). Incidence of metabolic changes among virus-resistant mutants of a bacterial strain. Proc. nat. Acad. Sci., Wash. 30, 397.

Arber, W. \& Kellenberger, G. (1958). Study of the properties of seven defectivelysogenic strains derived from Escherichia coli $\mathrm{K} 12(\lambda)$. Virology, 5, 458.

Ben-Gurion, R. \& Hertman, I. (1958). Bacteriocin-like material produced by Pasteurella pestis. J. gen. Microbiol. 19, 289.

De HaAn, P. G. (1954). Genetic recombination in Escherichia coli B II. The crossresistance of $E$. coli $\mathrm{B}$ to the phages T3, T4, and T7. Genetica, 27, 300.

DE MARs, R. I. (1955). The production of phage-related materials when bacteriophage development is interrupted by proflavine. Virology, $1,83$.

Delbrück, M. (1946). Bacterial viruses or bacteriophages. Biol. Rev. 21, 30.

Demerec, M. \& Fano, U. (1945). Bacteriophage-resistant mutants in Escherichia coli. Genetics, 30, 119.

FAstier, L. B. (1949). An antibiotic substance produced by a member of the Shigella group. J. Immunol. 62, 399.

Fredericq, P. (1946a). Sur la spécificité des actions antibiotiques. Schrweiz. Z. allg. Path. 9, 385.

Frederica, P. (1946b). Sur la pluralité des recepteurs d'antibiose de E. coli. C.R. Soc. Biol., Paris, 140, 1189. 
Fredericq, P. (1947). Recherche comparée des propriétés biochimiques et des propriétés antibiotiques dans le groupe Coli-Aerogenes. Bull. Soc. Chim. biol., Paris, 29, 358.

FredericQ, P. (1948a). Production de substances antibiotiques par certaines souches de Shigella. C.R. Soc. Biol., Paris, 142, 399.

FredericQ, P. (1948b). Antibiotiques réciproques chez les Enterobacteriaceae. Rev. belg. Path. (Suppl. 4), 19, 1.

FredericQ, P. (1949). Sur la résistance croisée entre colicine $\mathrm{E}$ et bactériophage II. C.R. Soc. Biol., Paris, 143, 1011.

FredericQ, P. (1952). Recherche des propriétés lysogènes et antibiotiques chez les Salmonella. C.R. Soc. Biol., Paris, 146, 298.

Frederice, P. (1954). Induction de la production de colicine par irradiation ultraviolette de souches colicinogènes d'Escherichia coli. C.R. Soc. Biol., Paris, 148, 1276.

Frederice, P. (1955). Induction de la production de colicine et de bactériophages par irradiation ultraviolette de souches colicinogènes et lysogènes d'Escherichia coli. C.R. Soc. Biol., Paris, 149, 2028.

FredericQ, P. (1957). Genetics of two different mechanisms of resistance to colicins. In CIBA Foundation Symposium on Drug Resistance in Micro-organisms. Boston: Little, Brown and Co.

Frederice, P. (1958). Colicins and colicinogenic factors. Symposia Soc. Exp. Biol. 12, 104.

FredericQ, P. \& Betz-Bareau, M. (1952). Recombinants génétiques de souches marquées par résistance aux colicines et aux bactériophages. Ann. Inst. Pasteur, 83, 283.

FredericQ, P. \& Gratia, A. (1950). Rapports entre colicines et bactériophages du groupe T1-T7. Ant. v. Leeurwenhoek, 16, 119.

Furness, G. \& Rowley, D. (1957). The presence of the transmissible agent $F$ in nonrecombining strains of Escherichia coli. J. gen. Microbiol. 17, 550.

Goebel, W. F., Barry, G. T. \& Shedlovsky, T. (1956). Colicine K. I. The production of colicine $\mathrm{K}$ in media maintained at constant pH. J. exp. Med. 103, 577.

Gratia, A. (1925). Sur un remarquable exemple d'antagonism entre deux souches de Colibacille. C.R. Soc. Biol., Paris, 93, 1040.

Gratia, A. (1932). Antagonism microbien et 'Bactériophagie'. Ann. Inst. Pasteur, 48, 413.

Hamon, Y. (1955). Étude d'une colicine élaborée par une culture de S. paratyphi B. Ann. Inst. Pasteur, 88, 193.

Hamon, Y. (1956). Les bactériocines sont-elles des substances antigéniques? C.R. Acad. Sci., Paris, 242, 1240.

Hamon, Y. \& Lewe, Z. V. (1955). Étude de l'induction par l'irradiation ultraviolette de quelques cultures d' $E$. coli K12 préablement rendues colicinogènes par transduction. Ann. Inst. Pasteur, 89, 336.

Hirota, Y. (1956). Artificial elimination of the F-factor in Bacterium coli, K-12. Nature, Lond. 178, 92.

Hrrota, Y. (1957) Acriflavine as an effective agent for eliminating F-factor in Escherichia coli K-12. Nature, Lond. 180, 655.

Ivanovics, G. \& AlföLdI, L. (1954). A new antibacterial principle: megacine. Nature, Lond. 174, 465.

Ivanovics, G. \& AlföLdi, L. (1955). Observations on lysogenesis in B. megaterium and on megacine, the antibacterial principle of this bacillus species. Acta microbiol. Acad. Sci., Hung., 2, 275.

Ivanovics, G. \& AlföLDI, L. (1957). Bacteriocinogenesis in Bacillus megaterium. J. gen. Microbiol. 16, 522.

Ivanovics, G., Alföldi, L. \& Lovas, B. (1957). Cultivation and electron microscopy of a bacteriocinogenic strain of Bacillus megaterium. Acta microbiol. Acad. Sci., Hung. 4, 295.

Ivanovics, G. \& NagY, E. (1958). Hereditary aberrancy in growth of some Bacillus megaterium strains. J. gen. Microbiol. 19, 407.

$\mathrm{J}_{\mathrm{ACOB}}$, F. (1954). Biosynthèse induite et mode d'action d'une pyocine, antibiotique de Pseudomonas pyocyanea. Ann. Inst. Pasteur, 86, 149. 


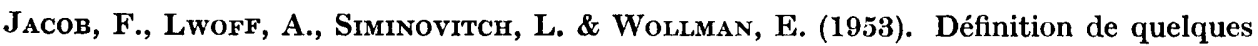
termes relatifs à la lysogènie. Ann. Inst. Pasteur, 84, 222.

Jacob, F., Siminovitch, L. \& Wollman, E. (1952). Sur la biosynthese d'une colicine et sur son mode d'action. Ann. Inst. Pasteur, 83, 295.

Keillenberger, G. \& Keluenberger, E. (1956). Étude de souches colicinogènes au microscope électronique. Schreeiz. Z. allg. Path. 19, 582.

LEDERBERG, J. (1947). Gene recombination and linked segregations in Escherichia coli. Genetics, 32, 505.

LIEB, M. (1951). Forward and reverse mutation in a histidine-requiring strain of Escherichia coli. Genetics, 36, 460.

Ludford, C. G. \& Lederer, M. (1953). The antibiotics of E. coli. Aust. J. exp. Biol. med. Sci. 31, 553.

Roepke, R. R., Libby, R. L. \& Small, M. H. (1944). Mutation or variation of Escherichia coli with respect to growth requirements. J. Bact. 48, 401.

Ryan, F. J. (1953). Natural selection in bacterial populations. Proc. Sixth Inter. Congr. Microbiol. 1, 649.

Ryan, F. J., Fried, P. \& Mukai, F. (1955). A colicin produced by cells that are sensitive to it. Biochim. biophys. Acta, 18, 131.

Ryan, F. J. \& SchneIDER, L. K. (1948). The consequences of mutation during the growth of biochemical mutants of Escherichia coli. I. The pattern of adaptation of histidineless cultures. J. Bact. 56, 699.

Ryan, F. J. \& Schneider, L. K. (1949). Mutations during the growth of biochemical mutants of Escherichia coli. Genetics, 34, 72.

ZAMENHOF, S. \& Greer, S. (1958). Heat as an agent producing high frequency of mutations and unstable genes in Escherichia coli. Nature, Lond. 182, 611. 